\title{
ASPECTOS FISIOANATÔMICOS DE PLANTAS JOVENS DE Cupania vernalis Camb. SUBMETIDAS A DIFERENTES NÍVEIS DE SOMBREAMENTO ${ }^{1}$
}

\author{
Érico de Castro Lima Jr. ${ }^{2}$, Amauri Alves de Alvarenga ${ }^{3}$, Evaristo Mauro de Castro ${ }^{4}$, Carlos Vinício Vieira ${ }^{5}$ e \\ João Paulo Rodrigues Alves Delfino Barbosa ${ }^{5}$
}

\begin{abstract}
RESUMO - Cupania vernalis Camb. (Sapindaceae) é uma espécie freqüente em quase todas as formações florestais, principalmente em Cerrado e Mata de Galeria, abrangendo os Estados de Minas Gerais, Mato Grosso e São Paulo até o Rio Grande do Sul. Essa espécie se destaca, principalmente, pelo seu emprego em plantios mistos destinados à recuperação de áreas degradadas de preservação permanente, pelo fato de seus frutos serem muito apreciados e consumidos por pássaros e, ainda, na medicina popular contra asma e tosses convulsivas. O estudo da anatomia foliar é de grande importância para a compreensão da plasticidade adaptativa de uma espécie submetida a diferentes condições ambientais, por estar correlacionada com processos de trocas gasosas e assimilação de $\mathrm{CO}_{2}$ e outras características inerentes ao crescimento da planta. Neste trabalho, objetivou-se estudar o efeito de diferentes níveis de sombreamento (pleno sol, 30\%, 50\% e 70\%) sobre a anatomia foliar e trocas gasosas de plantas jovens de Cupania vernalis Camb. Os resultados indicaram maior taxa fotossintética e, ainda, incrementos na condutância estomática, espessura do limbo, número de estômatos por área e espessura de parede celular em folhas de plantas crescidas sob pleno sol e 30\% de sombreamento. Foram observadas correlações positivas entre características de trocas gasosas e anatomia foliar. Pelos resultados, pôde-se concluir que a espécie em estudo apresenta grande plasticidade anatômica em relação aos níveis de sombreamento testados, favorecendo, assim, um melhor desenvolvimento das mudas sob diferentes condições ambientais.
\end{abstract}

Palavras-chave: Cupania vernalis Camb., fotossíntese, sombreamento e anatomia foliar.

\section{PHYSIOANATOMY TRAITS OF LEAVES IN YOUNG PLANTS OF Cupania vernalis camb. SUBJECTED TO DIFFERENT SHADING LEVELS}

\begin{abstract}
Cupania vernalis camb. (Sapindaceae) is a species commonly found in almost all forest associations, mainly in savanna-like vegetation (cerrado) and galeria woods, spreading over the states of Minas Gerais, Mato Grosso, São Paulo and reaching as far as Rio Grande do Sul. The species stands out mainly by its use in mixed planting to recover degraded areas of permanent preservation, for its fruits being much appreciated and consumed by birds and, still used in folk medicine against asthma and convulsive coughs. Leaf anatomy studies are highly important for the understanding of the adaptive plasticity of a species subjected to different environmental conditions, as it is correlated with processes such as gas exchanges and $\mathrm{CO}_{2}$ assimilation, as well as other processes inherent to plant growth. This work aimed to study the effect of different shading levels (full sunshine, 30\%, 50\% and 70\%) on leaf anatomy and gas exchanges of Cupania vernalis camb plantlets. The results showed greater photosynthetic rate, increase in stomatal conductance, blade thickness, number of stomata per area and thickness of cell wall on leaves of plants grown under full sunshine and $30 \%$ shading. Positive correlations were observed between gas exchange traits and leaf anatomy. Based on these results, it is possible to conclude that the species used in this study has a great anatomic plasticity in relation to the tested shading levels, supporting in this way a better development of the seedlings under different environmental conditions.
\end{abstract}

Keywords: Cupania vernalis Camb., photosynthesis, shading and leaf anatomy.

\footnotetext{
${ }^{1}$ Recebido em 07.07.2004 e aceito para publicação em 10.11.2005.

${ }^{2}$ Mestre em Agronomia/Fisiologia Vegetal, Dep. Biologia, UFLA.

${ }^{3}$ Departamento de Biologia, UFLA. Cx. Postal 3037, 37200-000 Lavras-MG.

${ }^{4}$ Departamento de Biologia, UFLA. Cx. Postal 3037, 37200-000 Lavras-MG.

${ }^{5}$ Bolsistas de Iniciação Científica, PIBIC/CNPq. Departamento de Biologia, UFLA, Lavras-MG.
} 


\section{INTRODUÇÃO}

Cupania vernalis Camb. é uma espécie conhecida popularmente como camboatã ou arco-de-peneira que habita tanto o interior de matas primárias quando em todos os estádios de formações secundárias. É descrita na literatura como uma espécie semidecídua, heliófita e seletiva higrófita, característica da floresta semidecídua de altitude e da mata pluvial atlântica. Trata-se de uma espécie de interesse ecofisiológico e econômico, podendo ser utilizada tanto na recuperação de áreas degradadas de preservação permanente quanto no paisagismo. Vale ressaltar também seu grande valor para a fauna, pois seus frutos são utilizados na alimentação, principalmente por pássaros (LORENZI, 2000), além do seu potencial medicinal, pois é utilizado na medicina popular contra asma e tosses convulsivas (RODRIGUES e CARVALHO, 2001).

A maioria dos projetos que visa à conservação e exploração de espécies nativas florestais depende da formação de mudas. Assim, a renovação da vegetação, a reconstituição de áreas degradadas, a produção de madeira e a obtenção de fitoterápicos são baseadas na coleta de sementes, reprodução e formação de mudas das espécies (MELLO et al., 1998; ALMEIDA, 2001; CAMPOS e UCHIDA, 2002).

Fatores como luz, temperatura, água e condições edáficas são alguns componentes do meio que influenciam, de maneira decisiva, o desenvolvimento da vegetação. Portanto, o suprimento inadequado de um desses componentes ou fatores pode reduzir o vigor da planta e limitar o seu desenvolvimento. Dentre esses fatores, a luz, especialmente nos planos qualitativo e quantitativo, age regulando vários processos do desenvolvimento, como a taxa de fotossíntese, biossíntese de pigmentos, assimilação de nitrogênio e anatomia foliar, entre outros processos (FERREIRA et al., 1977; SCHLUTER et al., 2003).

Alterações na estrutura interna foliar constituem aspectos decisivos na capacidade de aclimatação das espécies expostas a diferentes condições de ambiente (HANBA et al., 2002; SCHLUTER et al., 2003). Em adição, as características fotossintéticas geralmente variam em resposta a diferentes regimes de irradiância (BOARDMAN, 1977). Folhas de árvores crescendo num ambiente de sombra apresentam modificações nas características fotossintéticas, bioquímicas, organização de células do mesófilo e freqüência estomática quando comparadas com folhas crescendo num ambiente de maior irradiância (SIMS et al., 1998; SCHLUTER et al., 2003).

A difusão de $\mathrm{CO}_{2}$ no mesófilo depende da estrutura interna do limbo foliar e da organização das células do mesófilo. Todavia, a variação na condutância em resposta a diferentes níveis de radiação tem sido pouco estudada (EVANS e LORETO, 2000).

Este trabalho teve por objetivo avaliar os efeitos de diferentes níveis de irradiância em plantas de Cupania vernalis Camb. sobre as características anatômicas e fotossintéticas e respectivas inter-relações.

\section{MATERIAL E MÉTODOS}

O trabalho foi conduzido no Departamento de Biologia do Setor de Fisiologia Vegetal, da Universidade Federal de Lavras, durante o período de abril a novembro de 2003, sob condições de viveiro. As mudas foram oriundas de sementes coletadas em plantas-matriz localizadas no Município de Bom Sucesso, MG, às margens do Rio Grande, onde atualmente se localiza o reservatório da Usina Hidrelétrica do Funil.

As mudas foram cultivadas em bandejas de isopor contendo 144 células e, como substrato, terra de subsolo, areia e esterco bovino, na proporção de 7:2:1, e adubado com $2 \mathrm{~kg}$ de fertilizante $4: 14: 8 / \mathrm{m}^{3}$ de substrato. Posteriormente, as mudas foram transferidas para sacos de polietileno contendo $3 \mathrm{dm}^{3}$ do mesmo substrato, permanecendo em viveiro sob $30 \%$ de sombreamento por um período de cinco meses até se estabelecerem. Aos oito meses de idade, plantas jovens de Cupania vernalis Camb. foram submetidas a quatro níveis de sombreamento ( $0 \%$ ou pleno sol, 30,50 e $70 \%$ de sombreamento). Os níveis de 30, 50 e $70 \%$ foram obtidos por meio de telas pretas de náilon, conhecidas como "sombrite", conforme especificações do fabricante. Durante o período de condução do experimento, foram realizadas irrigações diárias e adubações mensais com solução nutritiva modificada de Johnson (1940).

Ao final do experimento foram analisadas as seguintes características: taxas de fotossíntese líquida, transpiração e condutância estomática, por meio do analisador portátil de gás infravermelho de fluxo aberto (LCA-4, Analytical Development Co., Hoddesdon, UK). Essas avaliações foram realizadas em um único dia, às 9 horas da manhã (hora solar), em folhas totalmente expandidas localizadas no terceiro nó, região superior 
de plantas. Para o estudo de anatomia foliar, foram utilizadas as mesmas folhas submetidas às avaliações de trocas gasosas.

O delineamento experimental utilizado foi o inteiramente casualizado, com os tratamentos representados por quatro níveis de luz $(70,50$ e $30 \%$ e pleno sol), com 25 repetições, sendo a unidade experimental constituída de uma planta. Os dados foram submetidos à análise de variância e testes de média, utilizando-se o programa SISVAR 4.3 (FERREIRA, 1999).

\subsection{Microscopia de luz}

As folhas submetidas a avaliações de trocas gasosas foram coletadas, posteriormente fixadas em álcool $70 \%$ e conduzidas ao laboratório, onde foram realizadas as confecções das lâminas para fins de estudos anatômicos. Os cortes foram realizados à mão livre, com a utilização de lâmina de barbear e submetidos, em seguida, à coloração com safranina e azul-de-astra, na proporção de 7:3. No caso específico para avaliações relativas à cutícula foi utilizado o corante Sudam IV.

A determinação da densidade estomática foi realizada por seções paradérmicas da epiderme na face abaxial. A contagem de estômatos foi realizada em microscópio Olympus CBB, com o auxílio de uma câmara clara, segundo metodologia descrita por Labouriau et al. (1961), em quatro campos da região mediana de 10 folhas provenientes de 10 plantas distintas, perfazendo-se um total de 40 campos por tratamento.

A espessura foliar foi avaliada por meio de seções transversais de lâminas semipermanentes de 10 folhas provenientes de 10 plantas distintas, sendo as medições realizadas pelo microscópio KEN-A-VISION 2100 equipado com uma Ocular Micrométrica. As medidas foram realizadas em três campos por folha, perfazendose um total de 30 medições para cada tecido foliar por tratamento.

O índice estomático $(\mathrm{Si})$ foi calculado por meio da seguinte fórmula: $\mathrm{Si}(\%)=[\mathrm{Sn} /(\mathrm{Sn}+\mathrm{Em})] \times 100$, sendo (Sn) o número de estômatos e (Em) o número de células da epiderme. As observações e as documentações foram realizadas em fotomicroscópio Olimpus BX 60.

\subsection{Microscopia eletrônica de transmissão (MET)}

As preparações e a observação das amostras para a MET foram realizadas no Laboratório de Microscopia de Precisão do Departamento de Fitopatologia da
Universidade Federal de Lavras, em Lavas, MG. Foram coletados pedaços de $1 \mathrm{~mm}^{2}$ de cinco folhas de cada tratamento, localizadas no $3^{\circ}$ nó abaixo do ápice e fixadas em solução (Karnovisk's modificado), pH 7,2 por um período de $24 \mathrm{~h}$, lavados em tampão cacodilato (três vezes de $10 \mathrm{~min}$ ), pós-fixados em tetróxido de ósmio $1 \%$ em água por 1 hora, lavados por duas vezes de 15 min em água destilada, transferidos para solução $0,5 \%$ de acetato de uranila durante $12 \mathrm{~h} \mathrm{a} 4{ }^{\circ} \mathrm{C}$ e em seguida, lavados novamente em água destilada e desidratados em gradiente de acetona $(30,50,70,90$ e $100 \%$ por três vezes). Em seguida, o material foi incluído em gradiente crescente de Spurr/acetona 30\% (8 h), $70 \%$ ( $12 \mathrm{~h})$ e $100 \%$ duas vezes por $24 \mathrm{~h}$ cada, sendo os espécimes montados em moldes e colocados para polimerizar em estufa a $70^{\circ} \mathrm{C}$ por $48 \mathrm{~h}$.

Em seguida, foram realizados os cortes em seções semifinas $(1 \mathrm{~mm})$ e ultrafinas $(<100 \mathrm{~nm})$, utilizandose um ultramicrotomo Reichrt-Jung (ultracut), com o auxílio de navalha de diamante. Os cortes semifinos foram coletados com anel de ouro, colocados em lâminas de vidro, coloridos com azul-de-toluidina ( $1 \mathrm{~g}$ azulde-toluidina, $1 \mathrm{~g}$ de borato de sódio e $100 \mathrm{~mL}$ de água purificados por meio de filtro Millipore $0,2 \mathrm{~mm}$ ) e montados permanentemente em meio Permalt. Os cortes ultrafinos foram coletados em grades de ouro ("golden slot grids"), secados em raques de alumínio cobertos com formvar (ROWLEY e MORAN, 1975). As seções foram póscontrastadas em acetato de uranila, seguido por acetato de chumbo por três minutos cada e, em seguida, examinadas em microscópio eletrônico de transmissão Zeiss, modelo EM 109 a $80 \mathrm{Kv}$.

\section{RESULTADOS E DISCUSSÃO}

As plantas cultivadas sob 50 e $70 \%$ de sombreamento apresentaram menores taxas de fotossíntese líquida quando comparadas com os demais tratamentos avaliados. As plantas submetidas a 70\% de sombreamento foram as que exibiram menor condutância estomática em relação às cultivadas sob maiores intensidades luminosas (Figuras 1bc).

Quanto à transpiração, de maneira geral não foram observadas diferenças entre os tratamentos (Figura 1a), muito embora tenham sido verificados aumento na condutância estomática e incremento concomitante na fotossíntese líquida em níveis mais elevados de irradiância, demonstrando uma relação direta entre essas duas características (Figuras 1bc).

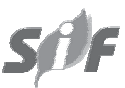

R. Árvore, Viçosa-MG, v.30, n.1, p.33-41, 2006 


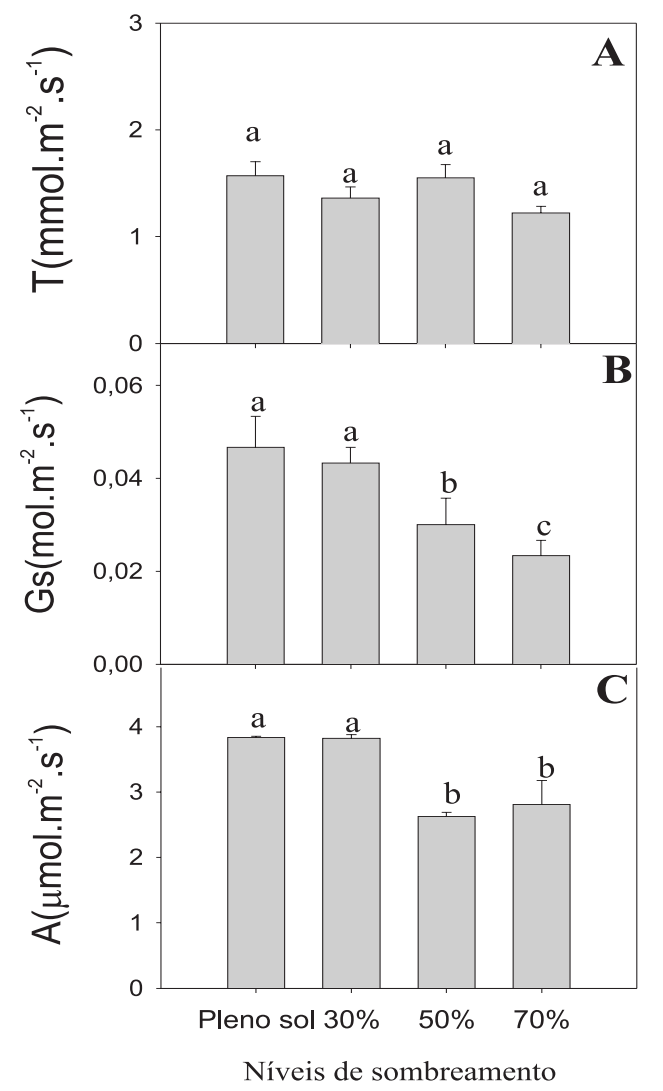

Figura 1 - Taxa fotossintética (A), condutância estomática (Gs) e transpiração (T) em plantas de C. vernalis Camb. submetidas a diferentes níveis de sombreamento. Médias seguidas pela mesma letra não diferem entre si, pelo teste de Tukey a 5\%.

Figure 1 - Photosinthetic rate (A), stomatic conductance (Gs) and transpiration (T) in C.vernalis Camb.plants subjected to different shading levels. Means followed by the same letter did not differ by the Tukey Test at $5 \%$.
Vários trabalhos vêm sendo realizados para se estudar o efeito de diferentes níveis de radiação sobre a estrutura foliar e trocas gasosas (SIMS et al., 1998; ALVARENGA et al., 2003; SCHLUTER et al., 2003).

Em Croton urucurana Baill, uma espécie pioneira, Alvarenga et al. (2003) verificaram também que as maiores taxas fotossintéticas ocorreram em plantas jovens cultivadas em níveis mais elevados de irradiância (30\% e a pleno sol).

Trabalhando com espécies tolerantes e sensíveis à sombra, Ramos e Grace (1990) observaram resultados com tendências semelhantes, em que os maiores valores de condutância estomática foram observados em plantas tolerantes cultivadas a pleno sol.

Em plantas de Quercus robur, Welander e Ottosson (2000) observaram que as taxas transpiratórias foram maiores com o aumento da irradiância.

Os resultados obtidos em plantas de C. vernalis corroboram os de Piel et al. (2002). Esses autores verificaram que plantas de Juglans regia cultivadas a pleno sol apresentaram maiores taxas de fotossíntese e condutância estomática, confirmando a citada relação entre essas duas características.

Maior espessura do limbo de folhas de C.vernalis foi observada em plantas cultivadas sob sol pleno, seguidas das plantas cultivadas sob 30, 50 e $70 \%$ de sombreamento, respectivamente (Tabela 1).

A espessura do parênquima paliçádico e das epidermes das faces abaxial e adaxial foi a que mais contribuiu para a maior espessura do limbo nas plantas cultivadas a pleno sol, uma vez que não foram observadas diferenças significativas $(\mathrm{P}>0,05)$ na espessura do parênquima esponjoso (Tabela 1).

Tabela 1 - Espessura das epidermes abaxial e adaxial, parênquimas paliçádico e esponjoso e espessura total do limbo foliar de plantas jovens de C. vernalis Camb. submetidas a diferentes níveis de sombreamento

Table 1 - Abaxial and adaxial epiderm thickness in spongy and palisade parenchyma and leaf thickness in young plants of C. vernalis camb. subjected to different shading levels

\begin{tabular}{|c|c|c|c|c|c|}
\hline \multirow[b]{2}{*}{$\begin{array}{l}\text { Níveis de } \\
\text { Sombreamento }\end{array}$} & \multicolumn{5}{|c|}{ Espessura $(\mu \mathrm{m})$} \\
\hline & $\begin{array}{c}\text { Ep. } \\
\text { Adaxial }\end{array}$ & $\begin{array}{c}\text { Ep. } \\
\text { Abaxial }\end{array}$ & $\begin{array}{l}\text { Parênquima } \\
\text { Paliçádico }\end{array}$ & $\begin{array}{l}\text { Parênquima } \\
\text { Esponjoso }\end{array}$ & $\begin{array}{l}\text { Espessura } \\
\text { do Limbo }\end{array}$ \\
\hline Pleno sol & $25,50 \quad a$ & 8,40 a & 85,80 a & $50,10 \mathrm{a}$ & 169,53 a \\
\hline $30 \%$ de sombreamento & $18,75 \quad b$ & $5,70 \mathrm{~b}$ & $60,60 \mathrm{~b}$ & $53,10 \mathrm{a}$ & $138,15 \mathrm{~b}$ \\
\hline $50 \%$ de sombreamento & $15,15 \mathrm{c}$ & $6,00 \mathrm{~b}$ & $48,00 \mathrm{c}$ & $50,40 \mathrm{a}$ & $119,55 \mathrm{c}$ \\
\hline $70 \%$ de sombreamento & $16,35 \mathrm{bc}$ & 7,80 a & $49,35 \mathrm{c}$ & $45,60 \mathrm{a}$ & $119,10 \mathrm{c}$ \\
\hline
\end{tabular}

*As médias seguidas pela mesma letra, nas colunas, não diferem entre si, a 5\% de probabilidade, pelo teste de Tukey. 
Pôde-se verificar, ainda, que os espaços intercelulares no mesófilo das folhas submetidas a $70 \%$ de sombreamento foram maiores, em comparação com essa mesma característica das folhas a pleno sol (Figura 2).

Vários trabalhos com espécies lenhosas têm mostrado maior espessamento do mesófilo e redução dos espaços intercelulares em folhas de plantas cultivadas a pleno sol, em relação às cultivadas em níveis mais elevados de sombreamento (ASHTON e BERLYN, 1992; NAKAZONO et al., 2001; PIEL et al., 2002).
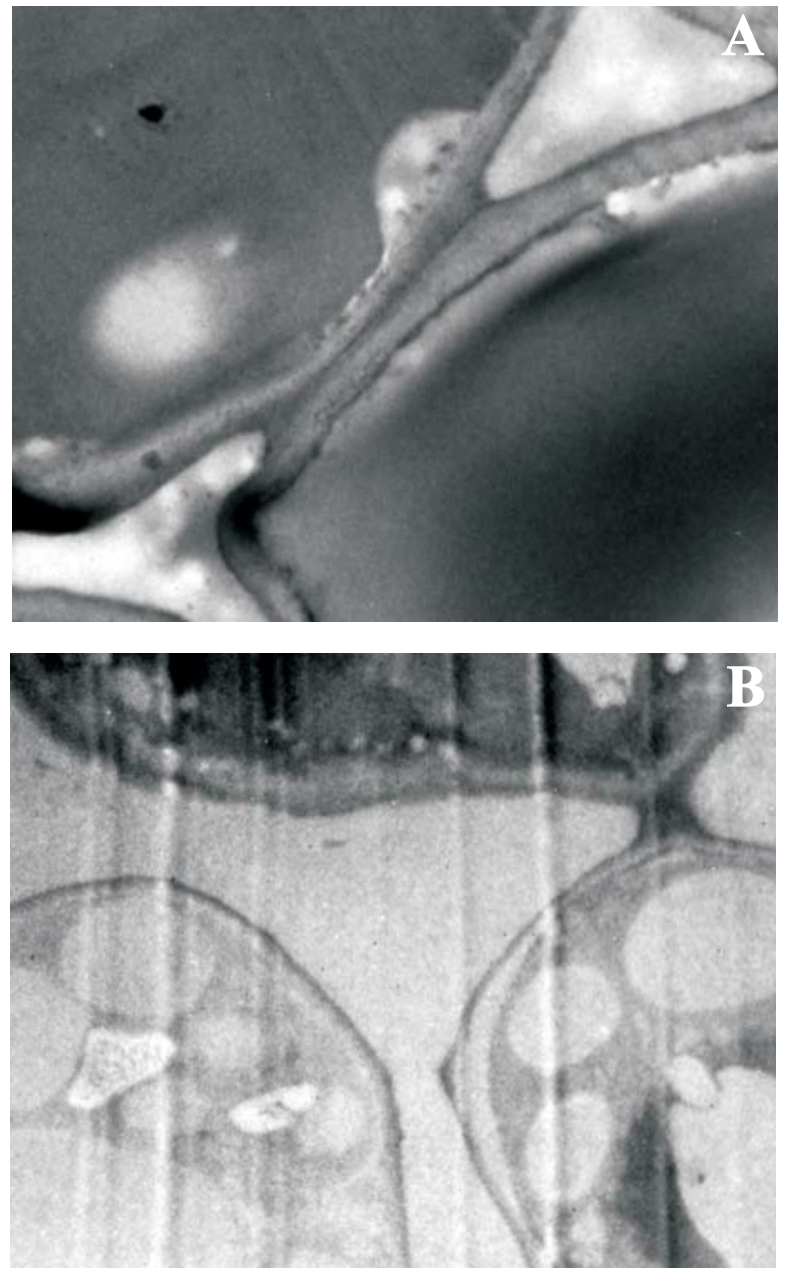

Figura 2 - Eletrofotomicrografias em seções transversais de lâminas foliares de Cupania vernalis submetidas a diferentes níveis de sombreamento, A (pleno sol; $7000 \mathrm{X})$ e B (70\% de sombra; $3000 \mathrm{X})$.

Figure 2 - Eletromicrography in transversal section of $C$. vernalis leaves subjected to different shading levels (Full sunligth, 7000X; 70\% shading , 3000X).
Em três espécies de Acer (A. palmatum, A. mono e A. rufinerve), Hanba et al. (2002), avaliando o efeito de diferentes níveis de irradiância sobre a anatomia foliar, verificaram que todas as espécies apresentaram maior espessamento no mesófilo com o aumento da radiação. Esse maior espessamento também se deveu a um parênquima paliçádico mais espesso.

O decréscimo na espessura do limbo foliar de plantas de C. vernalis cultivadas em níveis mais elevados de sombreamento pode ter ocorrido em virtude da diferença na distribuição de fotoassimilados. Em condições de baixa irradiância, as plantas apresentaram folhas mais delgadas, devido ao consumo de assimilados para a expansão da área foliar (COOPER e QUALLS, 1967; SERT, 1992).

Foram observadas diferenças marcantes entre os tratamentos, com relação às paredes das células dos parênquimas paliçádico e esponjoso. As paredes das células de ambos os tecidos foram mais espessas em folhas de plantas crescidas a pleno sol, em comparação com as cultivadas sob $70 \%$ de sombreamento (Tabela 2).

De acordo com as teorias que explicam a ação morfogenética da radiação solar, segundo Rizzini (1976), plantas submetidas a maiores níveis de irradiância apresentam, geralmente, elevadas concentrações de açúcares solúveis e, como conseqüência, aumento da pressão osmótica celular, causando diminuição no teor de água dos tecidos. Dessa maneira, há um déficit hídrico nas folhas, o qual gera um desvio de água dos meristemas.

Tabela 2 - Espessura da parede celular em células dos tecidos paliçádico e esponjoso de folhas de $C$. vernalis Camb. submetidas a diferentes níveis de sombreamento

Table 2-Cell wall thickness from cells of palisade and spongy tissues of C.vernalis subjected to different shading levels

\begin{tabular}{lcc}
\hline $\begin{array}{l}\text { Níveis de } \\
\text { Sombreamento }\end{array}$ & $\begin{array}{c}\text { Esp. da Parede } \\
\text { de Células do } \\
\text { Paliçádico }(\eta \mathrm{m})\end{array}$ & $\begin{array}{c}\text { Esp. da Parede } \\
\text { de Células } \\
\text { do Esponjoso }(\eta \mathrm{m})\end{array}$ \\
\hline Pleno sol & 656,6 a & 348,3 a \\
$70 \%$ sombreamento & $483,1 \mathrm{~b}$ & $206,5 \mathrm{~b}$ \\
CV $(\%)$ & 20,35 & 6,83 \\
\hline
\end{tabular}

*As médias seguidas pela mesma letra nas colunas não diferem entre si, a $5 \%$ de probabilidade, pelo teste de Tukey.

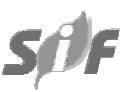

R. Árvore, Viçosa-MG, v.30, n.1, p.33-41, 2006 
Em conseqüência, o crescimento das células na fase de alongamento é reduzido, e o crescimento em expansão das paredes celulares paralisa antes do que deveria, tendendo, por isso, a tornar-se mais espessas. O resultado final é a formação de células menores e com maior espessura de parede.

Segundo Evans (1999), há uma relação estreita entre espaços intercelulares e espessuras de parede celular na condutância interna de $\mathrm{CO}_{2}$. Essa condutância é constituída de dois componentes, ou seja, a difusão de gases através dos espaços intercelulares e a difusão líquida entre a parede celular e os sítios de carboxilação.

No presente estudo, foram observados maiores espaços intercelulares (Figura 2) e menores espessuras de parede (Tabela 2) em folhas de C.vernalis submetidas a níveis mais elevados de sombreamento, favorecendo, assim, maior condutância interna de $\mathrm{CO}_{2}$ e maior distribuição interna de $\mathrm{CO}_{2}$ nas folhas dessas plantas.

A partir de observações de seções paradérmicas em lâminas foliares, verificou-se que o número de estômatos por área, o número de células e o índice estomático foram superiores em plantas cultivadas a pleno sol e 30\% de sombreamento (Figura 3a,c,d). Os estômatos das folhas das plantas submetidas a pleno sol e 50\% de sombreamento são menores em diâmetro equatorial, enquanto em relação ao diâmetro polar não foram verificadas diferenças entre os tratamentos (Figura 3b).

Esses resultados estão de acordo com os obtidos para outras espécies, nas quais geralmente ocorre aumento na freqüência e no no índice estomático com a elevação da irradiância (ABRAMS e MOSTOLLER, 1995; CASTRO et al., 1998; ATROCH et al., 2001; HANBA et al., 2002).

Aumento na densidade estomática pode permitir que a planta eleve a condutância de gases e, assim, evitar que a fotossíntese seja limitada sob diferentes condições de ambiente. Alguns trabalhos têm demonstrado correlações positivas entre número de estômatos e taxa fotossintética (KUNDU e TIGERSTEDT, 1998; CASTRO, 2002).

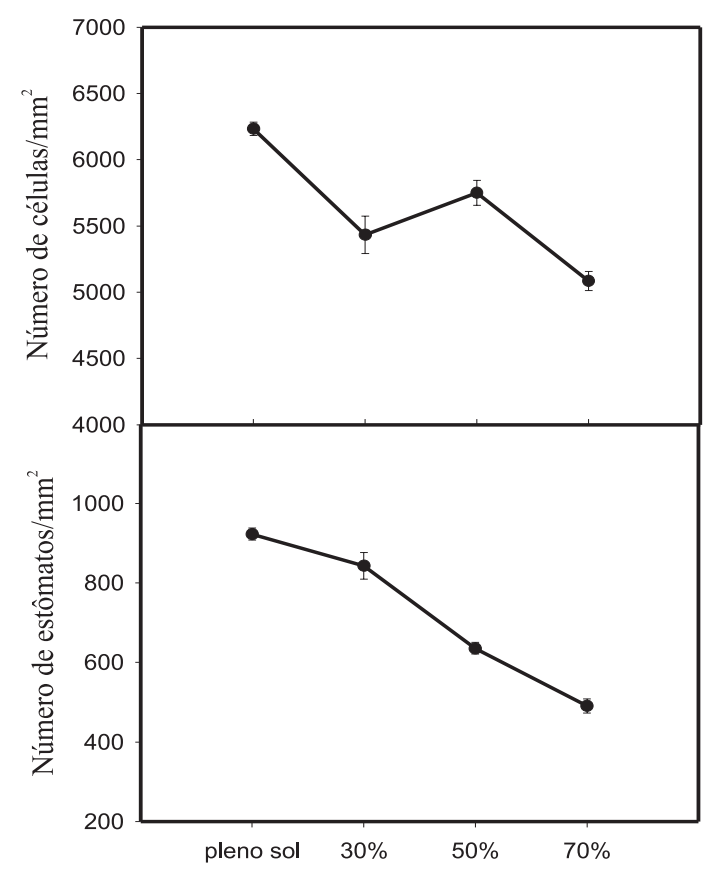

Níveis de sombreamento

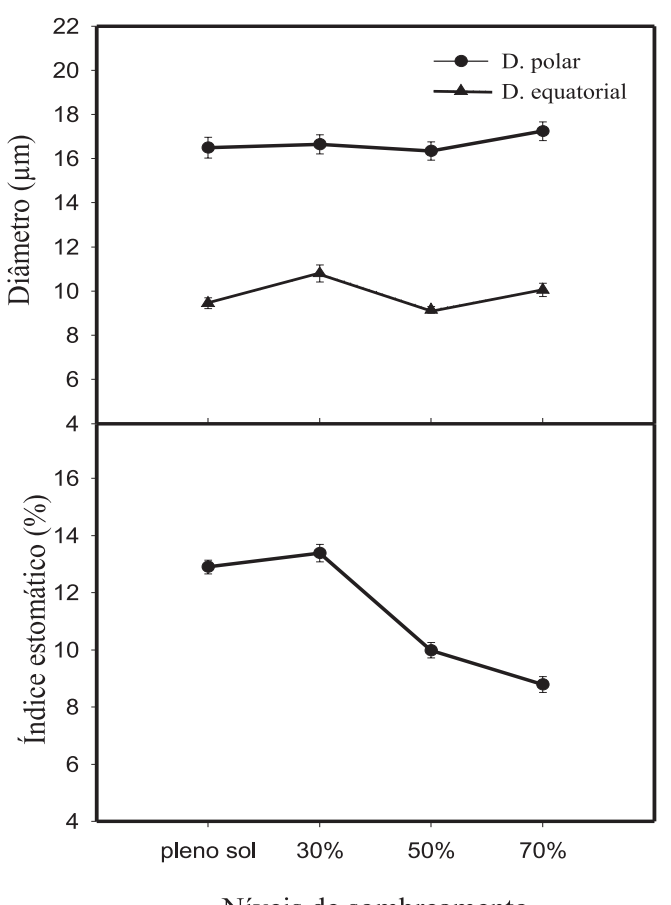

Níveis de sombreamento

Figura 3 - Número de células e estômatos por $\mathrm{mm}^{2}$, índice estomático e diâmetros polar e equatorial de folhas de plantas de C. vernalis Camb. submetidas a diferentes níveis de sombreamento.

Figure 3 - Stomata and cell number per $\mathrm{mm}^{2}$, stomatic index and equatorial and polar diameters from leaves of C. vernalis Camb. plants. 
Alguns autores como Atroch et al. (2001) e Klich (2000) não encontraram em seus trabalhos diferenças nos diâmetros dos estômatos em relação aos níveis de irradiância, a que as plantas foram submetidas. Entretanto, Castro et al. (1998) encontraram diferenças significativas apenas no diâmetro polar dos estômatos da espécie de Guarea guidonea, os quais foram maiores em folhas de plantas cultivadas em $50 \%$ de sombreamento.

De acordo com Voltan et al. (1992) e Morais et al. (2003), o aumento do sombreamento provoca redução no número de estômatos, e na espessura do mesófilo e incremento dos espaços intercelulares, e essas características estão relacionadas ao processo fotossintético.

As diferenças no número de estômatos observadas nas plantas de C.vernalis nos diferentes níveis de sombreamento refletiram diretamente na condutância estomática. Quanto maior o número de estômatos $/ \mathrm{mm}^{2}$, maior a condutância estomática (Figura $4 \mathrm{~b}$ ), portanto as plantas de Cupania cultivadas em níveis mais elevados de irradiância apresentaram menor resistência à difusão de gases. A freqüência estomática é um bom indicador da capacidade fotossintética, entretanto a condutância
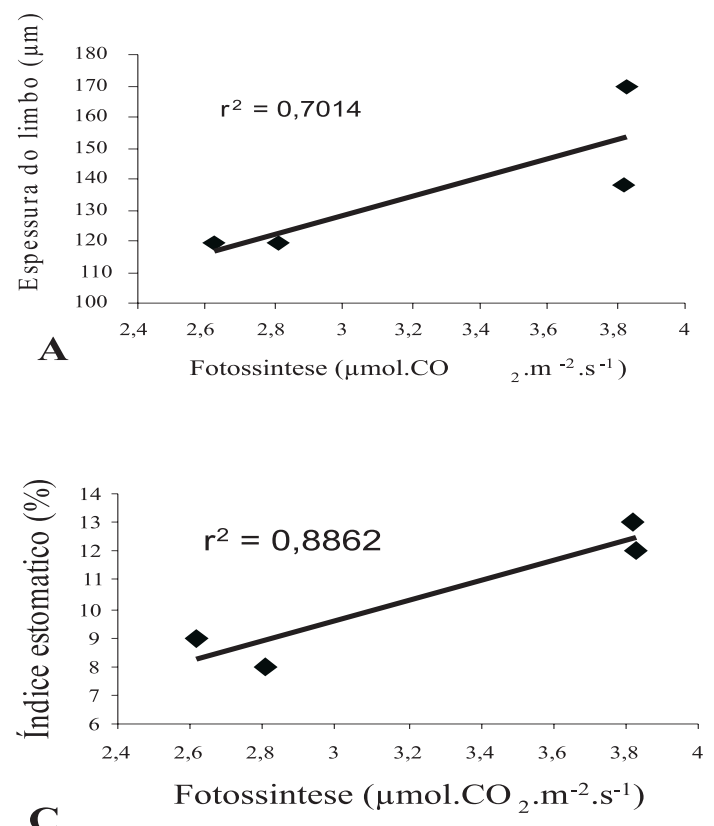

Figura 4 - Relações entre as características anatômicas e de trocas gasosas avaliadas em folhas de C. vernalis submetidas a diferentes níveis de sombreamento.

Figure 4-Relationship between anatomic characteristics and gaseous exchange evaluated in C. vernalis subjected to different levels of shading. estomática não depende somente do número de estômatos, mas também do seu tamanho (BJORKMAN e HOLMGREN, 1963).

Para Koslowski et al. (1991), a capacidade de resposta dos estômatos às variáveis ambientais são mais importantes para a determinação da condutância estomática do que o seu número.

Relações positivas entre transpiração, condutância estomática, índice estomático, número de estômatos, espessura do limbo e taxa fotossintética líquida foram verificadas no presente estudo (Figura 4). Todas essas características poderão ser utilizadas como indicadores da capacidade fotossintética em plantas de $C$. vernalis submetidas a diferentes níveis de sombreamento.

Diante dos resultados, verificou-se que a anatomia foliar pode influenciar a taxa de trocas gasosas e, assim, promover grandes diferenças na eficiência do uso da luz (ARAUS et al., 1986; SCHLUTLER et al., 2003), demonstrando que há uma plasticidade adaptativa em espécies que apresentam amplo potencial de aclimatização (BJORKMAN, 1981; SIMS et al., 1998; NAKAZONO et al., 2001; IVANOVA e P'YANKOV, 2002; PIEL et al., 2002; SCHLUTER et al., 2003).
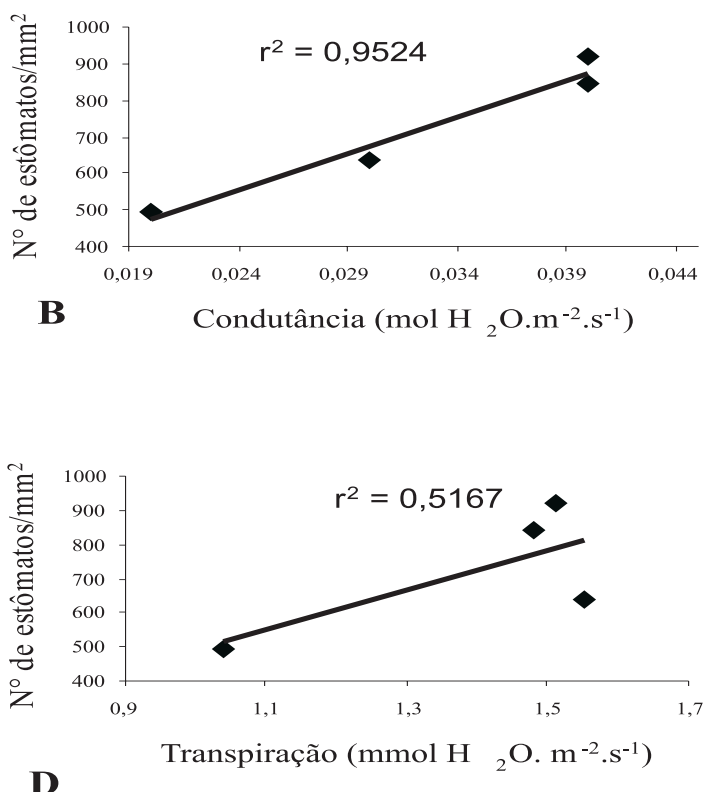

D

R. Árvore, Viçosa-MG, v.30, n.1, p.33-41, 2006 
As plantas de C. vernalis apresentaram uma grande plasticidade em relação aos diferentes níveis de irradiância estudados, alterando algumas características da anatomia foliar, as quais foram direta e positivamente relacionadas com características inerentes a trocas gasosas, como taxa fotossintética, condutância estomática e transpiração, favorecendo, assim, um melhor desenvolvimento das mudas sob diferentes condições ambientais.

\section{REFERÊNCIAS BIBLIOGRÁFICAS}

ABRAMS, M. D.; MOSTOLLER, S. A. Gas exchange, leaf struture and nitrogen in contrasting sucessional tree species growing in open and understory sites during a drought. Tree Physiology, v. 15, n. 6, p. 361-370, 1995.

ALMEIDA, L. P. Germinação, crescimento inicial e anatomia foliar de plantas jovens de Cryptocarya aschersoniana Mez. Sob diferentes níveis de radiação. 2001. 96 f. Dissertação (Mestrado em Fisiologia Vegetal) - Universidade Federal de Lavras, Lavras, 2001.

ALVARENGA, A. A. et al. Effects of diffrente light leveld on the initial growth and photosynthesis of Croton urucurana Baill. In southeastern Brazil. Revista Árvore, v. 27, n. 1, p. 53-57, 2003.

ARAUS, J. L. et al. Relationship between photosynthetic capacity and leaf structure in several shade plants. American Journal of Botany, v. 73, p. 1760-1770, 1996.

ASHTON, M. S.; BERLYN, G. P. Leaf adaptations of some Shorea species to sun and shade. New Phytologyst, v. 121, n. 4, p. 587-596, 1992.

ATROCH, E. M. A. C. et al. Crescimento, teor de clorofilas, distribuição de biomassa e características anatômicas de plantas jovens de Bauhinia forticata Link submetidas à diferentes condições de sombreamento. Ciência e

Agrotecnologia, v. 25, n. 4, p. 853-862, 2001.

BJORKMAN, O. Responses to different quantum flux densities. In: LANGE, O. L. et al. (Ed.).

Encyclopedia of plant physiology new series. Berlin: Springer-Verlag, 1981. v. 12a, p. 57-107.

BJORKMAN, O.; HOLMGREN, P. Adaptability of photosynthetic apparatus to light intensity in ecotypes from exposed and shade habitats. Physiologia Plantarum, v. 16, n. 4, p. 889-915, 1963.
BOARDMAN, N. K. Comparative photosynthesis of sun and shade plants. Annual Review of Plant Physiology, v. 28, p. 355-377, 1977.

CAMPOS, M. A. A.; UCHIDA, T. Influência do sombreamento no crescimento de mudas de três espécies amazônicas. Pesquisa Agropecuária Brasileira, v. 37, n. 3, p. 281-288, 2002.

CASTRO, E. M. et al. Aspectos da anatomia foliar de mudas de Guarea guidonea (L.) Sleumer, sob diferentes níveis de sombreamento. Daphne, v. 8, n. 3, p. 31-35, 1998.

CASTro, E. M. Alterações anatomicas, fisiologicas e fitoquimicas em plantas de Mikania glomerata Sprengel (guaco) sob diferentes fotoperiodos e níveis de sombreamento. 2002. 221 f. Tese (Doutorado em Fitotecnia) - Universidade Federal de Lavras, Lavras, 2002.

COOPER, C. S.; QUALLS, M. Morphology and chlorophyll content of shade and sun leaves of two legumes. Crop Science, v. 7, n. 6, p. 672-673, 1967.

EVANS, J. R. leaf anatomy enables more equal access to ligth and $\mathrm{CO}_{2}$ between chloroplasts. New Phytologist, v. 143, n. 1, p. 93-104, 1999.

EVANS, J.R.; LORETO, F. Aquisition and difusion of $\mathrm{CO}_{2}$ in highter plant leaves. In: LEEGOOD, R. C.; SHARKEY, T. D.; von CAEMMER. S. (Ed.). Photosynthesis physiology and metabolism. Dordrecht: Kluwer Academic Publishers, 2000. p. 321-351.

FERREIRA, D. F. SISVAR 4. 3- Sistema de analises estatísticas. Lavras: UFLA, 1999.

FERREIRA, M. G. M. et al. Efeito do sombreamento na produção de mudas de quatro espécies florestais nativas. Revista Árvore, v.1, n. 2, p. 121-133, 1977.

HANBA, Y. T.; KOGAMI, H.; TERASHIMA, L. The effects of growth irradiance on leaf anatomy and photosynthesis in Acer species differing in light demand. Plant Cell and Enviroment, v. 25, n. 8, p. 1021-1030, 2002.

IVANOVA, L. A.; P'YANKOV, V. I. Structural adaptation of the leaf mesophyll to shading. Russian Journal of Plant Physiology, v. 49, n. 3, p. 419-431, 2002. 
JOHNSON, D. A. Plant microtechinique, New York: Mcgraw - Hill, 1940. 523p.

KLICH, M. G. Leaf variations in Elaeagus angustifolia realted to enviroment heterogeneity. Enviroment and Experimental Botany, v. 44, n. 3, p. 171-183, 2000.

KOZLOWSKI, T.; KRAMER, P. I.; PALLARDY, S. G. The physiolological ecology of woody plants. London: Academic Press, 1991. 657 p.

KUNDU, S. K.,; TIGERSTEDT, P. M. A. Variation in net photosynthesis, stomatal characteristics, leaf area and whole plant phytomass production among ten provenances of neem (Azadirachta indica). Tree Physiology, n.19, p. 47-52, 1998.

LABOURIAU, L. G.; OLIVEIRA, J. G.; SALGADOLABOURIAU, M. L. Transpiração de Schizolobium parahyba (Vell) Toledo I.

Comportamento na estação chuvosa, nas condições de Caeté, Minas Gerais. Anais da Academia Brasileira de Ciência, v. 33, n. 2, p. 237-257, 1961.

LORENZI, H. Árvores brasileiras: manual de identificação e cultivo de plantas arbóreas nativas do Brasil. 3.ed. Nova Odessa: Plantarum, 2000. v. 1 .

MELLO, J. T. Coleta, propagação e desenvolvimento inicial de espécies de cerrado. In: SANO, S. M.; ALMEIDA, S. P. (Eds.).

Cerrado: ambiente e flora. Planaltina-DF: Empresa Brasileira de Pesquisa Agropecuária, $1998.556 \mathrm{p}$.

MORAIS, H. et al. Características fisiológicas e de crescimento de cafeeiro sombreado com guandu e cultivado a pleno sol. Pesquisa

Agropecuária Brasileira, v. 38, n. 10, p. 1131-1137, 2003.

NAKAZONO, E. M. et al. Crescimento inicial de Euterpe edulis Mart em diferentes regimes de luz. Revista Brasileira de Botânica, v. 24, n.2, p. 173-179, 2001.

PIEL, C. et al. Effetc of local irradiance on $\mathrm{CO}_{2}$ transfer in wainut. Journal of

Experimental Botany, v. 53, n. 379, p.2423-2430, 2002.
RAMOS, J.; GRACE, J. The effetcs of shade on the gas exchange of seedlings of four tropical trees from México. Functional Ecology, v. 4, n. 5, p. 667-677, 1990.

RIZZINI, C. T. Tratado de fitogeografia do Brasil: aspectos ecológicos. São Paulo: HUCITEC, EDUSP, 1976. 327 p.

\section{RODRIGUES, V.E.G.; CARVALHO, D.A. Plantas medicinais no domínio dos cerrados. Lavras: UFLA, 2001. 180 p.}

SCHLUTER, U. et al. Photosyntetic performance of an Arabidopsis mutant with elevated stomatal density (sdd1-1) under different light regimes. Journal of Experimental Botany, v. 54, n. 383, p. 867-874, 2003.

SERT, M. A. Anatomia foliar e teores de clorofila em três variedades de soja0 [Glycine Max (L.) MEDRILL] e dois níveis de radiação solar. 1992. $66 \mathrm{f}$. Dissertação (Mestrado em Fisiologia Vegetal) Universidade Federal de Viçosa, Viçosa, 1992.

SIMS, D. A.; SEEMANN, J. R.; LUO, Y. Elevated $\mathrm{CO}_{2}$ concetration has independent effects on expansion rates thickness of soybean leaves across ligth and nitrogen gradients. Journal of Experimental Botany, v. 49, n. 320, p. 583591, 1998.

VOLTAN, R. B. Q., FAHL, J. L.; CARELLI, M. L. C. Variações na anatomia foliar de cafeeiros submetidos a diferentes intensidades luminosas. Revista Brasileira de Fisiologia, v. 4, n.2, p. 99-105, 1992.

ROWLEY, C. R.; MORAN, D. T. A simple procedure for mounting wring wrinkle - free sections on formvar - coated slot grids. Ultramicrotomy, v.1, n.1, p. $151-155,1975$.

WELANDER, N. T.; OTTOSSON, B. The influence of low light, drought and fertilization on transpiration and growth in young seedllings of Quercus robur L. Forest Ecology and Management, v. 127, n. 1/3, p. 139-151, 2000.

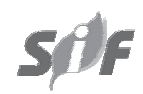

R. Árvore, Viçosa-MG, v.30, n.1, p.33-41, 2006 